\title{
Erosion-corrosion synergism for multi-phase flowline materials
}

\author{
Dr R.J.K. Wood \\ BP Research, Chertsey Road, Sunbury-on-Thames, UK. TW16 7LN. \\ Tel. : (0932) 764274, Fax : (0932) 764375.
}

\section{Introduction}

The present economics of oil production within BP impose a requirement to reduce costs on existing multi-phase oil and gas fields. A significant production cost is the frequent replacement of damaged flowline components. The list of components damaged not only include pipes but key multiphase equipment such as submersible pumps, control valves, topside seawater pumps and valves, pipeline elbows and tees, well head geometries and down hole tubulars. The damage is normally due to accelerated material wastage caused by either flow enhanced corrosion rates or the synergistic effect of erosion and corrosion. Corrosion rates, both downhole and in the flowlines, are influenced by the levels of carbon dioxide and hydrogen sulphide present as well as by the pipeline flow rate. Erosion is caused by the produced-sand impingement onto surfaces or the impingement of extremely turbulent flows. Erosioncorrosion of topside and subsea components, such as the seawater injection, fire water systems and some multiphase production control valves, results from the interaction of cavitation erosion and corrosion. This paper concentrates on the performance of metals subjected to erosion-corrosion in seawater or salt solution flows.
An understanding of the wear mechanisms involved is important if erosion-corrosion phenomena are to be controlled and flowline replacement costs reduced. This will become increasingly important as more remote fields are developed using higher production flow rates and under increasingly more corrosive conditions.

In recent years, several researchers have investigated the synergistic effects between erosion and corrosion to provide information to engineers designing or maintaining components subjected to both wear mechanisms. These workers have been involved in developing techniques to determine the synergism of cavitation erosion and corrosion [1-14]. In order to determine the synergism, both erosion and corrosion must be studied under controlled conditions. For cavitation erosion, either a vibrating-horn apparatus [5] or a hydrodynamic test tunnel [1] can be used. In the former case, erosion is controlled by varying the amplitude of vibration of the horn, which has either a sample attached to it or a static sample fixed a certain distance below it. The water tunnel has the facility to vary pressure and velocity in a flow stream section to produce cavitation downstream of a source (the source geometry can be varied to produce different types of cavitation). Although conditions such as amplitude or pressure and velocity can be fixed in such experiments, erosion rates still vary with time.

\section{Effets combinés de l'érosion et de la corrosion pour les matériaux des conduites d'écoulements polyphasiques}

Des matériaux spécialement concus pour les conduites d'écoulement, tels que l'acier, l'acier inoxydable super duplex, ainsi que des matériaux en contact avec l'eau de mer, tels que le cuivre et des alliages de cuivre-nickel, ont été évalués à différents niveaux de synergie résultant de l'interaction à la fois de la cavitation et de l'érosion par des particules solides avec la corrosion par l'eau de mer ou par des solutions salines à $3 \%$. Ces résultats, de même que des recherches publiées sur des phénomènes d'érosion-corrosion par cavitation et par des suspensions de sable, sont présentés et rassemblés sur une carte relative à l'usure dans les phénomènes d'érosion-corrosion. 
TABLE 1

SLURRY EROSION-CORROSION

$63 \mu \mathrm{m}$ SAND @ $2.25 \% \mathrm{wt}$ in distilled water or $3 \% \mathrm{NaCl}$ solution

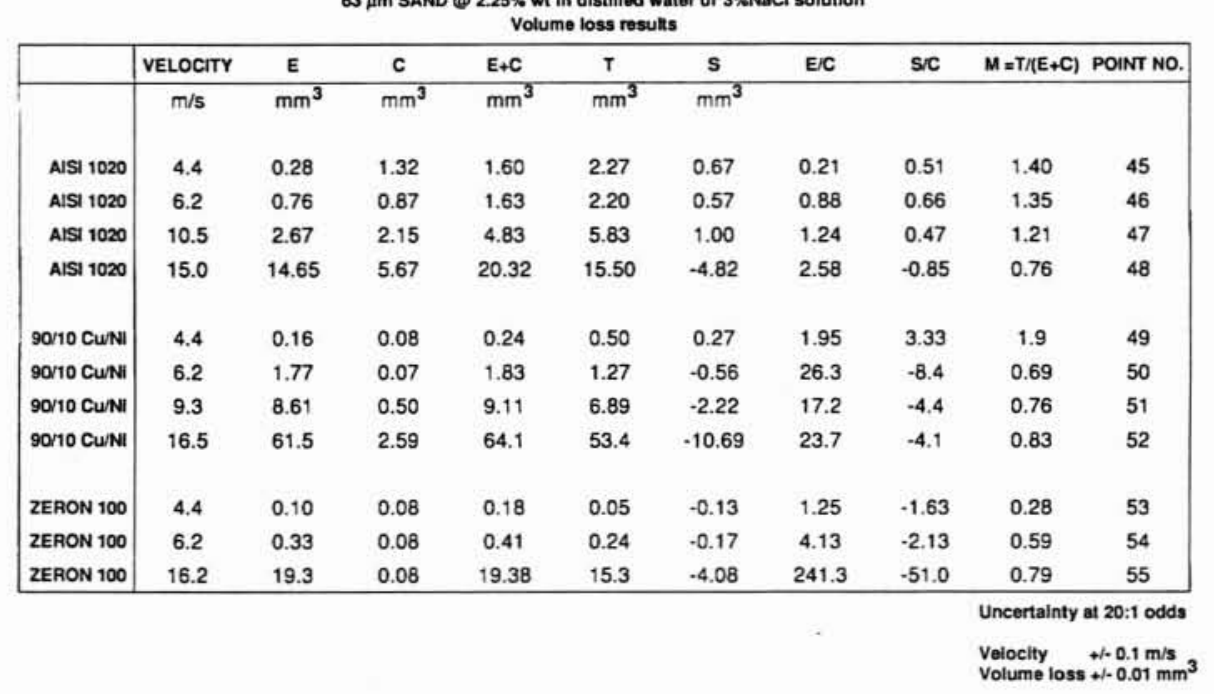

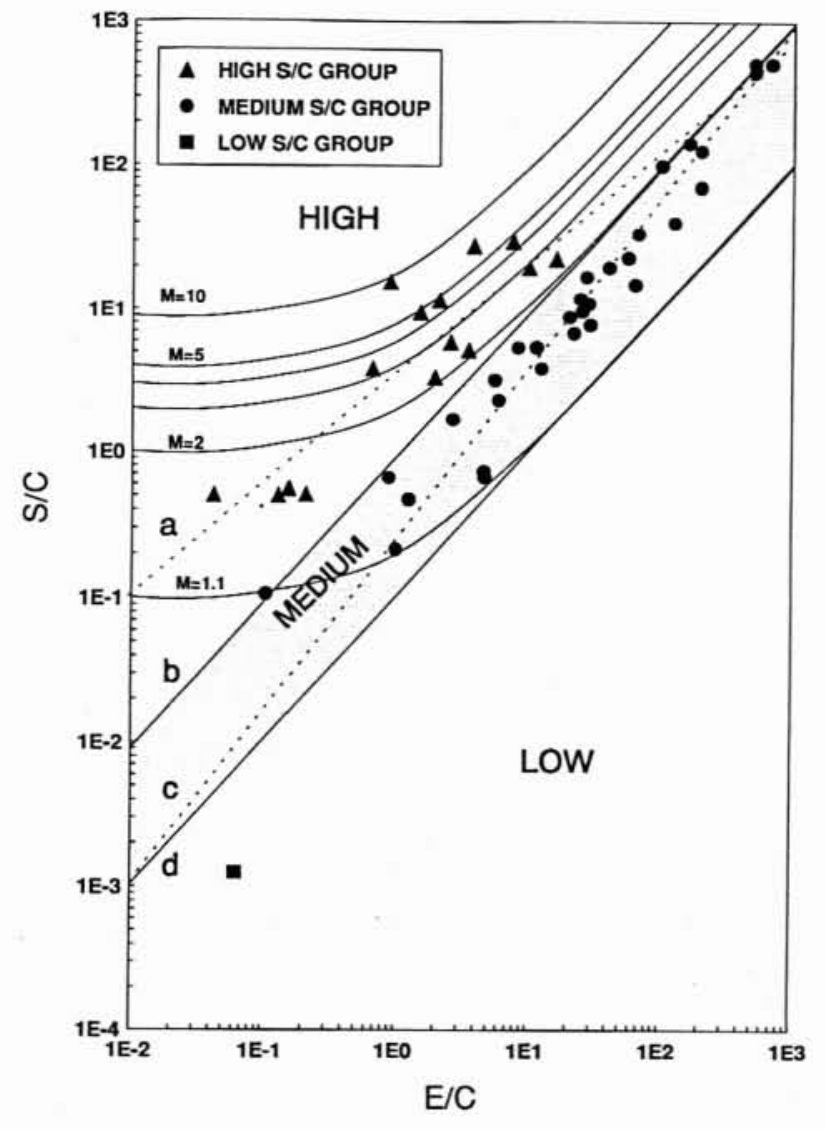

1. Erosion-corrosion wear map.
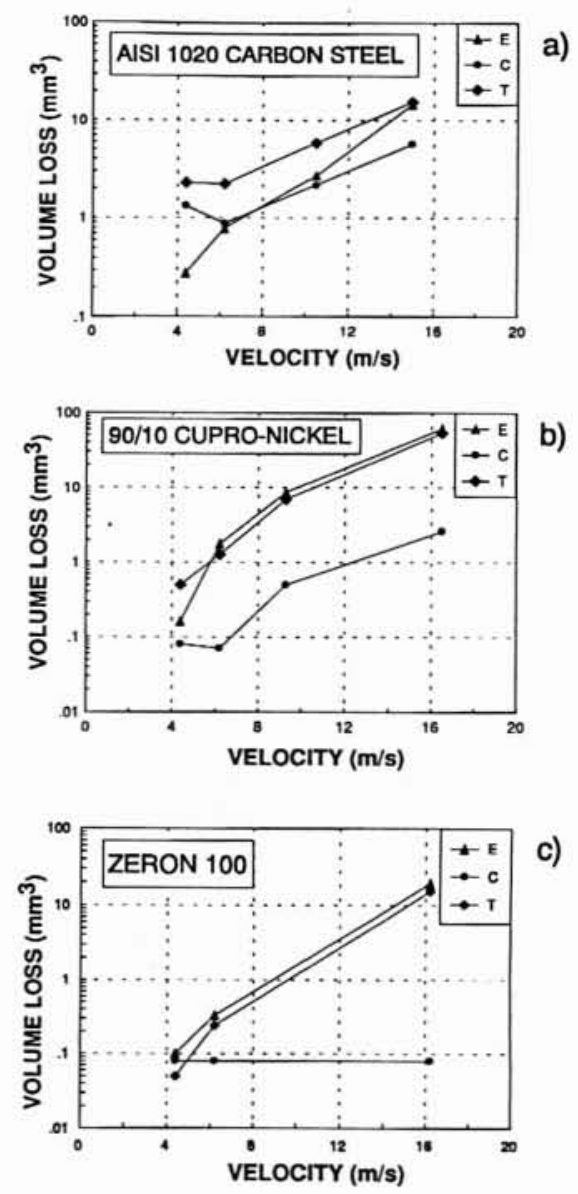

2. Slurry jet impingement erosion, corrosion and erosion-corrosion wear rates as a function of jet impingement velocity for a) AISI 1020 carbon steel, b) 90/10 cupro-nickel and c) Zeron 100. 
It is therefore important to establish steady state erosion regimes in each test. Similarly, it is important to impose a steady corrosion rate so that additional (synergistic) rates of wear above the sum of erosion and corrosion rates can be obtained. To obtain constant corrosion rates a potentiostat or galvanostat is used to control the electrical potential or current of the erosion sample $[1,6]$. Alternatively, the erosion sample can be eroded in corrosive media such as $3 \% \mathrm{NaCl}$ solutions [7] or acidic or alkaline solutions [8], with the corrosive wear rates being predetermined in separate experiments. The synergism can be determined from three types of test ; (1) pure erosion tests to determine the erosive wear rate ; (2) pure corrosion tests to determine the corrosion wear rate; (3) combined tests to determine the total wear rate when conditions in both test (1) and test (2) are acting. These experiments allow the synergism to be obtained as

$$
S=T-(E+C)
$$

where: $S=$ Synergistic wear rate; $T=$ Total wear rate (test 3$) ; E=$ Erosive wear rate (test 1); $C=$ Corrosive wear rate (test 2 ).

Wear rates may be determined as either mass loss, volume loss or depth of penetration rates. The synergistic wear rate $\mathrm{S}$ represents the summation of two separate factors, $\Delta E$, the additional erosive wear rate due to the presence of corrosion and, $\Delta C$, the additional corrosive wear rate due to the presence of erosion. The total wear rate $T$ in erosion-corrosion conditions is then

$$
T=E+C+\Delta E+\Delta C
$$

and the synergy, $S$, is

$$
S=\Delta E+\Delta C
$$

\section{Analysis of results from the literature and from recent experiments}

Although few experiments of the form described above have been reported, a need for uniformity in reporting results is required. This paper suggests adopting the erosion-corrosion wear map outlined in a recent paper by the author [9] for analysing both the cavitation erosioncorrosion and solid particle erosion-corrosion [9, 10] performance of flowline materials. The format of the wear map is to plot the ratio of synergistic wear to corrosive wear, $S / C$, against the ratio of erosive wear to corrosive wear, $E / C$. Figure 1 illustrates the $S / C$ vs. $E / C$ plot for the results published to date for metals tested in either $3 \%$ $\mathrm{NaCl}$ solutions or seawater combined with sand or cavitation erosion. The metals covered include AISI 1020 carbon steel, low alloy steels, copper, AISI 304 and 316 stainless steels. Some non-flowline metals such as pure iron [11] and grey cast iron [12] are also included. Additional metals reported subsequently are also plotted and include $16 \% \mathrm{Cr}$ White Cast Iron [13] and further in-house data for AISI 1020 carbon steel, 90/10 Cu/Ni and Zeron 100 super duplex stainless steel. These experiments were aimed at determining the conditions at which synergism occurred for the three metals.

Table 1 details sand erosion-corrosion experimental results obtained at the BP Research Centre, Sunbury-onThames. Tests involved a slurry jet of $2 \%$ wt sharp sand (mean diameter $63 \mu \mathrm{m}$ ) in either distilled or salt water, impinging at $90^{\circ}$ on the test specimens which were $35 \mathrm{~mm}^{2}$ in surface area. Variation in jet velocity was achieved both by controlling the flow rate and by varying the jet nozzle size between 6 and $10 \mathrm{~mm}$ diameter. Values of $E$ were obtained using a non-corrosive slurry of sand in deoxygenated distilled water. $C$ values were obtained from salt water impingement tests (no solids) with the metal targets freely corroding throughout the test duration. Sand and salt water slurries were used to evaluate $T$ levels for erosion-corrosion conditions. The synergistic wear rate, $S$, in terms of volume loss has been determined for various $E / C$ ratios. The resulting synergy is not always positive; combined effect of erosion and corrosion can be beneficial. Possible mechanisms for negative synergy are discussed later. $E, C$ and $T$ volume losses for these tests are plotted in figure 2.

Figure 1 shows that the results give evidence of three levels of synergistic response for metals under combined erosive and corrosive attack, representing high, medium and low $S / C$ categories. Points which lie between lines $b$ and $d$ on figure $l$ have medium synergism while points which lie above line $b$ have high synergism. Points below line $d$ have low or even negative synergism. It should be noted that a metal is not always found to be in one $S / C$ category but can have a widely varying $S / C$ value dependent on the ratio of erosion to corrosion rates $E / C$.

From figure 1 it is possible to fit a trend line to the points of the high and medium $S / C$ categories as follows:

High $S / C$ category (line $a$ on figure $I$ ).

$$
\ln (S / C)=0.76 \ln (\mathrm{E} / \mathrm{C})+1.22
$$

Medium $S / C$ category (line $c$ on figure 1 ).

$$
\ln (S / C)=1.28 \ln (E / C)-1.91
$$

For $E / C$ values above 50 , no distinction between the high or medium $S / C$ categories is possible. From equation (4), the high $S / C$ category can be seen to represent metals with synergism contributing over $30 \%$ of the total wear rate. The maximum synergy reported is that of plasma nitrided $16 \% \mathrm{Cr}$ white cast iron subjected to cavitation erosion-corrosion. It represents $90 \%$ of the total wear rate and a magnification of 9 times the expected $E+C$ wear rate. The medium $S / C$ category, equation (5), shows the level of synergism for this category to be below $30 \%$ of the total wear rate.

To illustrate the significance of the $S / C$ values in relation to the ratio $E / C$, the contours of the magnification factor, 


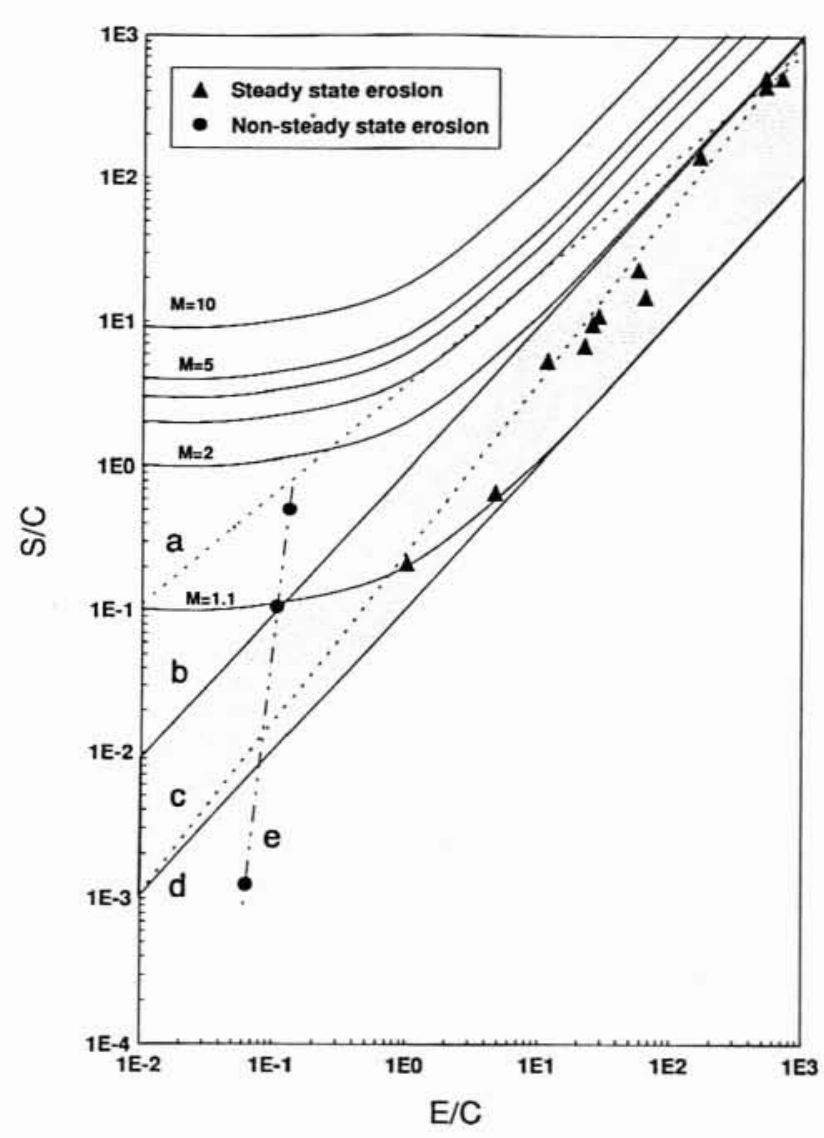

3. Copper (High conductivity BS 2874) erosion-corrosion wear map for hydrodynamic cavitation erosion in seawater for nonsteady state and steady state erosion.

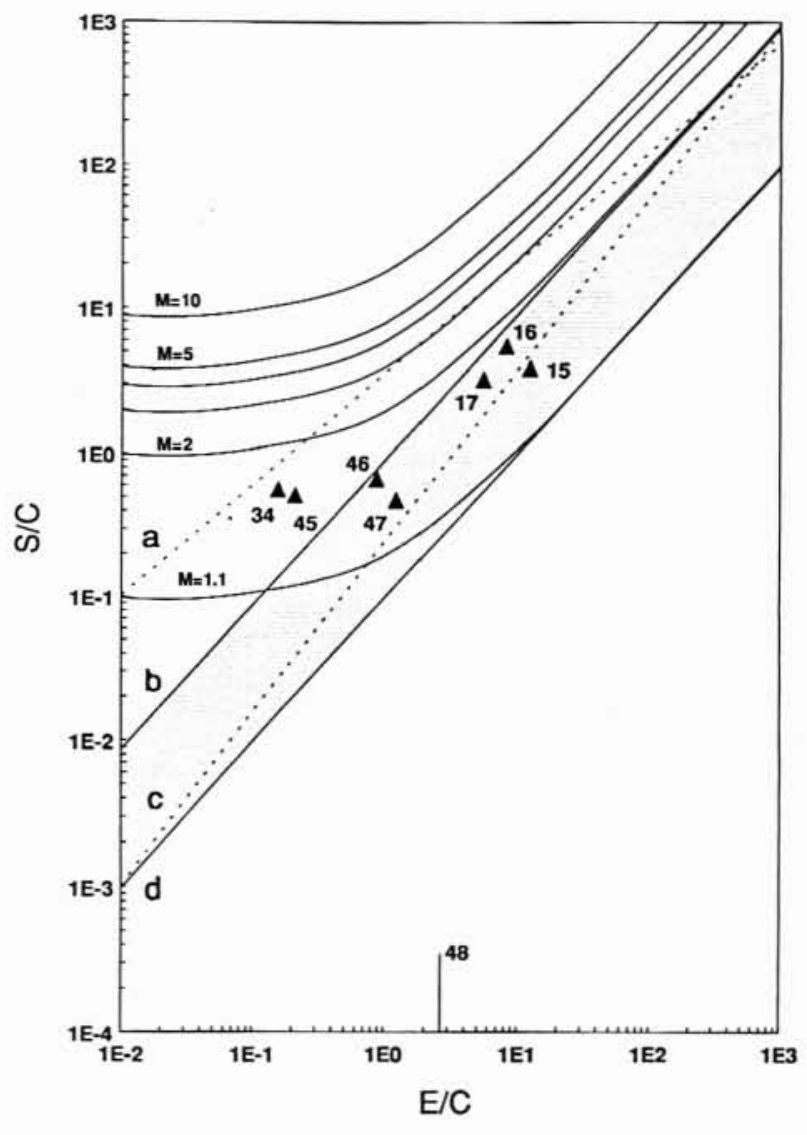

4. Carbon steel (AISI 1020) erosion-corrosion wear map. Points 15 to $17 \& 34$ are for vibratory cavitation in $3 \% \mathrm{NaCl}$ solutions. Points 45 to 48 are for 90 degree sand $/ 3 \% \mathrm{NaCl}$ solution slurry impingement erosion.
$\mathrm{M}$, have been plotted on figure 1 , where $M$ is the ratio of actual to expected wear rates:

$$
M=T /(E+C)
$$

From figure 1 the high $S / C$ category has a maximum $M$ of 3 between $E / C$ of 1 and 10 . The medium $S / C$ category have a maximum $M<2$ for high $E / C$ values.

Although the results available for such erosioncorrosion analysis are limited, wear maps for carbon steel, stainless steels and copper are given in figures 3-5 and discussed below. Such maps emphasize the need for a full evaluation of such materials as the magnification factor varies with operating severity. As only one point exists for $70 / 30$ and $90 / 10$ copper-nickel a wear map is not presented. The $70 / 30 \mathrm{Cu} / \mathrm{Ni}$ shows $\mathrm{M}=1.5$ at $E / C=29$ under cavitation erosion-corrosion while $90 / 10 \mathrm{Cu} / \mathrm{Ni}$ shows $M=1.9$ at $E / C=2$ under slurry erosion-corrosion. Higher sand slurry erosion rates produced negative synergy for $90 / 10 \mathrm{Cu} / \mathrm{Ni}$ at $E / C>2$ as detailed in table 1 .

\subsection{Copper erosion-corrosion wear map}

Results for hydrodynamic cavitation erosion-corrosion for copper are mapped in figure 3. For pure copper the synergistic wear rate follows the trend for medium synergistic risk equation (4). The synergy between erosion and corrosion has a maximum effect at high $E / C$ ratios where small corrosion rates are associated with a wear magnification factor of 2. The body of results for copper are for steady state erosion conditions. However, three points for copper in non-steady state erosion just after the incubation period [14] are plotted on figure 3 (line $e$ ). These points show that the synergism $S$ has a much stronger dependence on the inverse of corrosion rate than the steady state equivalents. Overall levels of erosion-corrosion synergy for copper seem low.

\subsection{Carbon steel erosion-corrosion wear map}

Figure 4 maps the smaller amount of data available for AISI 1020 . For $E / C>1$ the $S / C$ ratio lie on the medium 


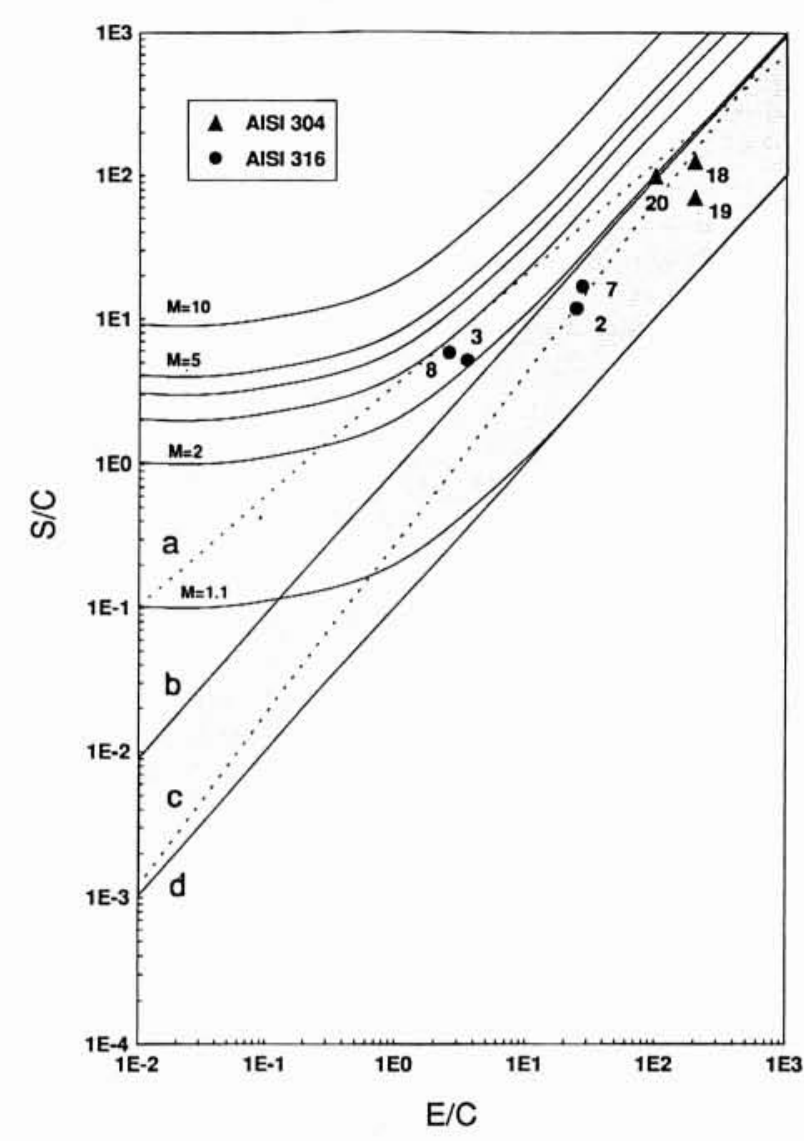

5. Stainless steel (AISI $304 \& 316)$ erosion-corrosion wear map. Points 18 to 20 are for vibratory cavitation in $3 \% \mathrm{NaCl}$ solution. Points $2,3,7 \& 8$ are for 90 degree sand $3 \% \mathrm{NaCl}$ solution slurry impingement erosion.

risk line $b$ drawn on the figure. Although for lower $E / C$ ratios the $S / C$ values remain high the resulting magnification due to synergistic mechanisms is never over 2. Point 48 from table 1 illustrates that at high slurry impingement velocities negative $S$ values are determined. The reason for this is not clear but it might be associated with work hardening of the metal surface or with the interaction of a corrosion product layer with the eroding flow stream. On this limited base of evidence it would appear that carbon steel is only at medium risk to synergism.

\subsection{Stainless steels erosion-corrosion wear map}

Available data points for stainless steels are shown in figure 5. Significant synergistic levels are found for AISI 316 at $E / C$ of 2 . The levels of $S$ translate into a $M$ factor of 2.7 at these conditions indicating that stainless steels are susceptable to erosion-corrosion attack. AISI 304 has only been tested at high $E / C$ ratios and yields maximum $M$ values of 2. More work is required for such materials. Sand erosion-corrosion results for Zeron 100, a super duplex stainless steel, show very good erosion-corrosion performance as $M$ is always below unity. From Figure 2 it can also be seen that Zeron 100 has excellent flow corrosion resistance, with the corrosion rate being low and independent of impingement velocity.

\section{Synergism}

The trends for both medium and high $\mathrm{S} / \mathrm{C}$ categories could be explained if the synergism is one of erosion-enhanced corrosion $\Delta \mathrm{C}$. Erosion has the effect of mechanically stripping the corrosion film by near-surface cavitation bubble collapse or solid particle impingement. Once the passivating corrosion films have been removed, fresh highly reactive corrosion sites are generated producing $\Delta \mathrm{C}$. The level of $\Delta \mathrm{C}$ will depend on the rate of repassivation of such sites and the integrity of the film formed. Synergism is thus expected at low corrosion levels and low to medium erosion rates when the possibility of rapid repassivation of freshly generated surfaces is low. Measurements of $\Delta \mathrm{C}$ made for copper under hydrodynamic cavitation erosioncorrosion indicate a $20 \%$ contribution to the synergism S $[1,2]$. This means that the $\Delta \mathrm{E}$ term is dominant with an $80 \%$ contribution. The dominance of $\Delta \mathrm{E}$ has also been found for white and grey cast irons $[12,13]$ where $\Delta C$ has a maximum contribution to $\mathrm{S}$ of $13 \%$. It was also noted that $\Delta \mathrm{C}$ was not measurable for copper until erosioninduced mass loss had occurred [2]. The presence of cavitation during incubation does not generate a synergy.

Other possible erosion-enhanced corrosion mechanisms include (i) local acidification in the erosion pits, accelerating corrosion rates and prohibiting film formation, (ii) increased ion transportation by high turbulence levels caused by surface roughening and (iii) lowering of the fatigue strength of the metal by corrosion. Corrosionenhanced erosion mechanisms are also possible and, as mentioned above, could be the dominant form of synergism in most cases. The $\Delta \mathrm{E}$ wear rate could be due to (iv) the removal of work hardened surfaces by corrosion processes which expose the softer base metal to erosion mechanisms, (v) preferential corrosive attack at grain boundaries resulting in grain loosening and eventual removal, and (vi) the increase in the number of stressconcentrations defects resulting from corrosion micropitting.

Most of these mechanisms, if dominant, would be expected to lead to an increase in the synergism with increasing corrosion rate. In practice the reverse is seen (see figures 3 to 5 ). Therefore, negative synergistic mechanisms must be influencing what is certainly a complex surface interaction. Possible mechanisms which reduce erosion rates $(-\Delta \mathrm{E})$ are (vii) increased work hardening due to corrosion mechanisms, (viii) shot-peening $[15,16]$ by high velocity sand particle impacts or (ix) the presence of a soft or loosely adhered corrosion film. The reduction in corrosion rates $(-\Delta C)$ could result from $(x)$ rapid corrosion film growth or the formation of a passive film reducing corrosion rates dramatically. 


\section{Conclusions}

Although much further experimental work is required, notably involving $\mathrm{CO}_{2}$ and $\mathrm{H}_{2} \mathrm{~S}$ corrosion, the present $\mathrm{E} / \mathrm{C}$ $v s$. $\mathrm{S} / \mathrm{C}$ wear maps provide a useful framework to guide research and to give present information to engineers in a useable fashion. The following detailed conclusions can be made :

a) The synergism of erosion and corrosion can be positive or negative. Only the former would be of concern to the designer, of course.

b) The erosion-corrosion resistance of flowline materials is dependent on the relative magnitude of erosive to corrosive wear.

c) The dominant synergistic wear mechanism may be that of corrosion-enhanced erosion $(\Delta \mathrm{E})$. Tests on copper under high intensity cavitation attack in seawater showed $\Delta \mathrm{C}$ to make a maximum contribution of $20 \%$ to the synergistic wear rate. The $\Delta \mathrm{C}$ contribution for grey and white cast irons in cavitating $3 \% \mathrm{NaCl}$ solutions is only $3-13 \%$ of the synergistic wear rate. d) $\Delta \mathrm{C}$ values appear to be related to material loss.

e) Zeron 100 super duplex stainless steel offers negative synergism over the slurry impingements conditions tested while results for AISI 316 show significant synergistic effects for $\mathrm{E} / \mathrm{C}$ values around 2.

f) Carbon steel AISI 1020, 90/10 cupro-nickel, AISI 304 and pure copper appear only to be at medium risk to synergistic effects which at worst doubles the expected wear rate $(E+C)$.

g) The maximum synergism reported was for plasma nitrided $16 \% \mathrm{Cr}$ white cast iron under cavitation erosion in $3 \% \mathrm{NaCl}$ solution. The synergy magnified the expected wear rate by 9 times.

\section{Acknowledgments}

Permission to publish this paper has been granted by the British Petroleum company plc.

\section{References}

[1] R.J.K. Wood and S.A. FrY. - The synergistic effect of cavitation erosion and corrosion for copper and cupro-nickel in seawater. J. Fluids Eng., 111 (1989), 271-277.

[2] R.J.K. WOOD and S.A. FRY. - Corrosion of pure copper in flowing seawater under cavitating and non-cavitating flow conditions. J. Fluids Eng., 111 (1990), 218-224.

[3] R.J.K. Wood, S.P. Hutton and D.J. Schiffrin. - Mass transfer effects of non-cavitating seawater on the corrosion of $\mathrm{Cu}$ and 70-30 Cu-Ni, Corros. Sci. J., 30 (12) (1990), $1177-$ 1201.

[4] R.J.K. WooD. - Use of profilometric measurements in cavitation erosion and corrosion studies. Proc. Inst. Mech. Eng., London, Part C, 204 (1990), 63-65.

[5] T. OKADA and K. AwAZv. - Fundamental studies on cavitation erosion. Bull. JSME, 24 (189) (1981), 461-467.

[6] R. Simoneau, J.L. Finey and R. Roberge. - The effect of corrosion in low intensity cavitation erosion. Proc. Symp. on Cavitation Erosion, Boulder, CO, June 1981, ASME, New York, (1981), 71-81.

[7] T. OKADA. - Corrosive liquid effects on cavitation erosion. J. Ship. Res., 25 (4), (1981), 271-274.

[8] Y. OKA and M. Matsumura. - Cavitation erosioncorrosion. Proc. 6th Int. Conf. on Erosion by Liquid and Solid impact, University of Cambridge, (1983), paper 11.
[9] R.J.K. WOOD and S.P. HUTTON. - The synergistic effect of erosion and corrosion : trends in published results. Wear 140 (1990), 387-394.

[10] B.W. MADSEN. - Measurement of erosion-corrosion synergism with the slurry wear test apparatus. Wear, 123 (1988), 127-142.

[11] Y. OKa, M. Matsumura and M. Yamawaki. - Slurry erosion-corrosion on commercially pure iron in a vibratory testing facility - mechanism of erosion-corrosion under predomintantly erosion conditions. Proc. 7th Int. Conf. on Erosion by Liquid and Solid Impact, University of Cambridge, (1987), paper 39.

[12] W.J. TomLinson and M.G. TALKS. - Cavitation erosion of grey cast irons containing 0.2 and $1.0 \%$ phosphorous in corrosive waters. Tribo. Int., 22 (3) (1989), 195-204.

[13] W.J. TomLinson and M.G. TALKs. - Laser surface processing and the cavitation erosion of a $16 \% \mathrm{Cr}$ White cast iron. Wear, 139 (1990), 269-284.

[14] S.A. FRY and R.J.K. Wood. - The synergistic effect of cavitation erosion and corrosion, 3rd progress report, Rep. ME/85/21, Department of Mechanical Engineering, University of Southampton, (1985).

[15] E.F. Beutin, F. ERdmanN-Jesnitzer, A.M. Hassen and H. Louis. - A new technique in the application of a high speed water jet. Proc. 3rd Int. Symp. on Jet Cutting Technology. Research Institute, Illinois Institute of Technology, Chicago II, (1976) paper F2.

[16] A. Lichtarowicz. - Unpublished results. Department of Mechanical Engineering, University of Nottingham (1989). 